\title{
HPV Vaccine for Adolescent Males: Acceptability to Parents Post-Vaccine Licensure
}

\author{
Paul L. Reiter, PhD ${ }^{1,2}$, Annie-Laurie McRee, MPH' ${ }^{1}$, Sami L. Gottlieb, MD ${ }^{3}$, and Noel T. \\ Brewer, PhD $^{1,2}$ \\ ${ }^{1}$ UNC Gillings School of Global Public Health, Chapel Hill, North Carolina \\ ${ }^{2}$ Lineberger Comprehensive Cancer Center, Chapel Hill, North Carolina \\ ${ }^{3}$ Centers for Disease Control and Prevention, Atlanta, Georgia
}

\author{
Keywords \\ HPV vaccine; Acceptability; Males
}

\section{Introduction}

\begin{abstract}
Human papillomavirus (HPV) infection is an extremely common sexually transmitted infection (STI) in the United States (U.S.) [1], with most estimates of prevalence among asymptomatic males over $20 \%$ [2,3]. Infection can occur soon after sexual debut, and the risk increases with the introduction of new sexual partners [4]. Although most HPV infections in males clear within one year without intervention [5], persistent infections can have serious health consequences. Oncogenic HPV types (mainly types 16 and 18) are responsible for almost all anal cancers, $40 \%$ of penile cancers, and $25 \%-35 \%$ of oral cancers [6,7]. Nononcogenic HPV types 6 and 11 cause genital warts [8,9], a diagnosis reported by about $4 \%$ of men in the U.S [10]. Female partners of HPV-infected males are at increased risk of cervical disease [11,12].
\end{abstract}

The U.S. Food and Drug Administration (FDA) approved a quadrivalent HPV vaccine against types 6, 11, 16, and 18 for use in females aged 9-26 years in 2006 [13]. The Advisory Committee on Immunization Practices (ACIP) currently recommends routine vaccination of females aged 11-12 years with catch-up vaccination for females through age 26 [13]. Recently, the FDA approved the quadrivalent HPV vaccine for use in males aged 926 years [14], as it was found to be efficacious in reducing the incidence of persistent HPV

\footnotetext{
(C) 2010 Elsevier Ltd. All rights reserved.

Correspondence and requests for reprints should be sent to: Paul L. Reiter, PhD, University of North Carolina Gillings School of Global Public Health, Department of Health Behavior and Health Education, 323D Rosenau Hall, CB 7440, Chapel Hill, NC 27599-7440, Tel: 919-966-8650, Fax: 919-966-2921, preiter@email.unc.edu. Second corresponding author: Noel T. Brewer, PhD, UNC Gillings School of Global Public Health, Department of Health Behavior and Health Education, 325 Rosenau Hall, CB 7440, Chapel Hill, NC 27599-7440,ntb1@unc.edu.

Publisher's Disclaimer: This is a PDF file of an unedited manuscript that has been accepted for publication. As a service to our customers we are providing this early version of the manuscript. The manuscript will undergo copyediting, typesetting, and review of the resulting proof before it is published in its final citable form. Please note that during the production process errors may be discovered which could affect the content, and all legal disclaimers that apply to the journal pertain.

Conflicts of Interest

Although we do not believe we have any conflicts of interest, we wish to share the following information in the interest of full disclosure. Authors have received research grants from Merck \& Co., Inc. (NB, PR) and GlaxoSmithKline (NB), but neither has received honoraria or consulting fees from these companies. These funds were not used to support this research study.
} 
infection and external genital lesions among young men [15,16]. Because HPV is an STI, vaccinating males against HPV may also have indirect benefit for females due to reduced transmission. In October 2009, the ACIP made a provisional permissive recommendation regarding use of HPV vaccine among males aged 9-26 years [17], which was published in final form in May 2010 [18]. The permissive recommendation states that healthcare providers may provide the vaccine to patients, but the vaccine is not included in the routine vaccination schedule for males. The ACIP also recommended the Vaccines for Children (VFC) program, which provides vaccines at no cost to children who may not otherwise be able to pay, cover quadrivalent HPV vaccine for males.

Adolescents constitute a large part of the age range for which HPV vaccine has been approved and shown to be efficacious in males [14]. Since parents typically decide whether their children receive vaccines, acceptability of HPV vaccine to parents is important. Studies have generally found that parents reported high levels of acceptability of giving HPV vaccine to their adolescent sons $[19,20]$. However, all of these studies were conducted prior to FDA approval of the vaccine for males, and many did not inform parents about the vaccine's health benefits for males or the vaccine's costs [19]. These factors may have influenced acceptability reported in these earlier studies. In this study, we aimed to characterize HPV vaccine acceptability following FDA approval of the vaccine for males among a national sample of mothers with adolescent sons.

\section{Materials and Methods}

\subsection{Participants and Procedures}

We used data from a study that recruited a national sample of mothers of adolescent females aged 11-14 years and examined mother-daughter communication about HPV vaccine. Some of these mothers also had adolescent sons aged 9-18 years, the focus of this report. All mothers were members of an existing national panel of U.S. households. The panel was composed using a dual frame approach combining list-assisted, random-digit dialing and address-based sample frames, which provided a probability-based sample of US households. The survey company provides households containing one or more panel members with free internet access in exchange for panel members completing multiple internet-based surveys each month. In households with existing computer and internet access, panel members accumulate points for completing surveys. The points can be redeemed for small cash payments at regular intervals.

The survey company invited 1,681 mothers to participate in our study, of whom 1,170 responded to the invitation. Among mothers who responded, 1,009 had a daughter aged 1114 years and were thus eligible to participate in the study. A total of 951 mothers of adolescent females (response rate $=66 \%$ [21]) provided informed consent and completed our cross-sectional, online survey in December 2009. Mothers who reported also having a son aged 9-18 years $(n=414)$ received items about HPV vaccination in males. If a mother had more than one son aged 9-18 years, she was asked to think about the son who had the most recent birthday when answering these items. We report data on HPV vaccine acceptability for 406 mothers, excluding mothers who indicated their sons had already received HPV vaccine $(n=2)$ and those who did not provide complete HPV vaccine acceptability data $(n=6)$. The Institutional Review Board at the University of North Carolina approved the study.

\subsection{Measures}

We developed survey items based on our previous HPV vaccine research among females, parents, and healthcare providers [22-24]. We cognitively tested the survey with mothers of 
adolescent children prior to the study to ensure survey instructions and items were clear and to confirm that participants interpreted survey items as we intended. The survey measured demographics and constructs we felt may be important to a study occurring only a few months post-HPV vaccine licensure for males.

Prior to asking mothers about their sons and HPV vaccine, the survey provided an informative statement about HPV vaccine and males: "An HPV vaccine is now available for use in boys and young men 9-26 years old. It protects against most genital warts and may provide some protection against different types of cancer, including oral and anal cancers. It requires 3 doses (or shots) over 6 months." The survey then assessed whether mothers had heard prior to this survey that HPV vaccine can be given to boys and whether their sons had received any doses of HPV vaccine.

To ensure that mothers were also aware that HPV vaccine may provide health benefits for their sons' sexual partners, the survey next provided mothers with a second informative statement: "Vaccinating boys against HPV may also provide protection against genital warts and cervical cancer for their future spouses or girlfriends." The survey measured how important it was to mothers that HPV vaccine may protect their sons' future spouses or girlfriends from HPV-related disease with a 4-point scale ranging from "not important at all" to "very important" (coded 1-4).

The survey then assessed mothers' willingness to get their sons HPV vaccine using two items: "How willing would you be to get the HPV vaccine for your son if it was free?" and "How willing would you be to get the HPV vaccine for your son if it cost $\$ 400$ out of pocket?". Response options were "definitely not willing," "probably not willing," "not sure," "probably willing," and "definitely willing" for both items (coded 1-5).

Mothers indicated if they had talked with their sons about HPV vaccine. The survey measured mothers' knowledge about HPV and HPV vaccine using three items about whether HPV is an STI, HPV vaccine can prevent most genital warts, and HPV vaccine prevents most cervical cancer. These items were asked prior to mothers receiving the informative statements about HPV vaccine and males. The survey provided response options of "yes", "no", and "I don't know" for each knowledge item. We summed the number of correct responses provided by each mother for the three items, coding responses of "no" and "I don't know" as incorrect. The survey also examined whether mothers' adolescent daughters (i.e., the adolescent sons' sisters) had received any doses of HPV vaccine.

In addition to their sons' ages, mothers provided information on various other demographic characteristics and health behaviors (Table 1). We defined "urban" as living in a metropolitan statistical area (MSA) and "rural" as living outside of an MSA [25]. The survey measured political affiliation with a 5-point scale ranging from "very conservative" to "very liberal" (coded 1-5), while importance of religion was measured with a 4-point scale ranging from "not important at all" to "very important" (coded 1-4).

\subsection{Data Analysis}

We used a paired $t$-test to compare mothers' willingness to get their sons HPV vaccine if the vaccine were free or cost $\$ 400$ out of pocket. We used linear regression to examine correlates of mothers' willingness to get their sons HPV vaccine if: 1) it were free, and 2) it cost $\$ 400$ out of pocket. We constructed a separate multivariate model for each outcome, though both models contained the same independent variables (those associated with either willingness outcome $(p<0.05)$ in bivariate analyses). We report standardized regression coefficients from these linear regressions. To determine if coefficients differed between the two models, we used repeated measures analysis of variance (ANOVA). Analyses used 
SPSS version 17.0 (SPSS Inc., Chicago IL), and statistical tests were two-tailed, using a critical alpha of 0.05 .

\section{Results}

\subsection{Participant Characteristics}

Most mothers were age 40 or older $(71 \%)$, non-Hispanic white (79\%), married or living with a partner (89\%), employed (67\%), and reported a household income of at least $\$ 60,000$ $(66 \%)$ (Table 1). Half of mothers had a college degree. The sample included mothers from all four geographic regions of the U.S. and primarily from urban areas (86\%). The mean age among sons was 13.2 years (standard deviation [SD]=2.8 years), with $42 \%$ aged $9-12$ years, $31 \%$ aged $13-15$ years, and $27 \%$ aged $16-18$ years.

\subsection{HPV and HPV Vaccine}

Mothers, on average, had fairly low knowledge about HPV and HPV vaccine, answering only $43 \%$ of the knowledge questions correctly (mean $=1.3$ of three items correct). Most knew that HPV is an STI (62\%), but fewer knew HPV vaccine can prevent most cervical cancer (47\%) and genital warts (20\%). About $30 \%$ of mothers' adolescent daughters aged 11-14 years had received any doses of HPV vaccine. Only $15 \%$ of mothers were aware prior to the survey that HPV vaccine can be given to boys, and fewer (10\%) had talked with their sons about the vaccine. Mothers thought it was important that HPV vaccine may protect their sons' future spouses or girlfriends from HPV-related disease (mean=3.0 [possible range 1-4], $\mathrm{SD}=1.1$ ).

\subsection{Willingness to Get Sons HPV Vaccine}

Mothers reported moderate levels of willingness to get their sons HPV vaccine if the vaccine were free (mean $=3.3$ [possible range $1-5$ ], $\mathrm{SD}=1.4$ ), with $47 \%$ definitely or probably willing to vaccinate (Figure 1). Mothers were less willing to get their sons HPV vaccine if the vaccine cost $\$ 400$ out of pocket (mean=2.1 [possible range 1-5], $\mathrm{SD}=1.1$ ) (paired $t=19.88$, $p<0.001$ ). Only $11 \%$ of mothers were definitely or probably willing to vaccinate if the three dose series cost $\$ 400$. Many mothers were not sure how willing they would be to vaccinate if the vaccine were free (25\%) or if it cost $\$ 400(26 \%)$.

In multivariate analysis, willingness to get their sons free HPV vaccine was higher among mothers who reported higher levels of importance that HPV vaccine may protect their sons' future spouses or girlfriends from HPV-related disease $(\beta=0.59)$ (Table 2). Mothers were also more willing to get their sons free HPV vaccine if they were aged 40-49 years (compared to those aged less than 40 years) $(\beta=0.08)$, not married or living with a partner ( $\beta=0.08)$, had higher HPV and HPV vaccine knowledge $(\beta=0.08)$, or if their adolescent daughters had received any doses of HPV vaccine $(\beta=0.15)$. Mothers who reported higher levels of religion importance $(\beta=-0.09)$ or were aware prior to the survey that HPV vaccine can be given to boys ( $\beta=-0.07)$ were less willing to get their sons free HPV vaccine.

Willingness to get their sons HPV vaccine if it cost $\$ 400$ out of pocket was higher among mothers who reported higher levels of importance that HPV vaccine may protect their sons' future spouses or girlfriends from HPV-related disease $(\beta=0.49)$, had higher HPV and HPV vaccine knowledge $(\beta=0.09)$, or had adolescent daughters who had received any doses of HPV vaccine ( $\beta=0.11$ ) (Table 2). Mothers were also more willing to pay $\$ 400$ to get their sons HPV vaccine if they were non-Hispanic African American (compared to non-Hispanic white $)(\beta=0.16)$ or reported a household income of at least $\$ 60,000(\beta=0.14)$. Non-Hispanic mothers of other races (not white or African American) reported lower willingness to pay for HPV vaccine than non-Hispanic white mothers $(\beta=-0.08)$. 
Several variables more strongly predicted mothers' willingness to get free HPV vaccine than willingness to pay for the vaccine (marital status, awareness that HPV vaccine can be given to boys, and importance that the vaccine may protect their sons' future spouses or girlfriends; all $p<0.05$ ) (Table 2). The opposite was true for race and household income, which were both more strongly associated with willingness to pay for the vaccine (both $p<0.05$ ). While estimates for political affiliation were on opposite sides of zero and differed in size from one another, political affiliation was not correlated with either willingness outcome.

\section{Discussion}

\subsection{Main Findings}

Soon after the ACIP gave a provisional permissive recommendation for HPV vaccination for males [17], a national sample of mothers with adolescent sons were moderately willing to get their sons free HPV vaccine but much less willing to pay $\$ 400$ out of pocket for the vaccine. To our knowledge, this is the first estimate of parents' willingness to get their sons HPV vaccine following FDA approval and provisional ACIP recommendations.

Acceptability of HPV vaccine for their adolescent son was lower than previous estimates among parents in the U.S. and elsewhere, which were typically well over 50\% $[19,20,26-$ 28]. This was somewhat surprising since many of these previous studies did not inform parents about the vaccine's potential health benefits for males and their sexual partners [19]. These studies, however, occurred prior to FDA licensure of HPV vaccine for males in the U.S., meaning acceptability estimates could have been inflated since vaccination was hypothetical. Our findings may more accurately represent parents' actual HPV vaccine acceptability for adolescent males.

Our results also highlight the importance of health insurance coverage for HPV vaccination in males, as mothers' willingness to vaccinate their sons was much lower if the vaccine cost $\$ 400$ out of pocket. While many health insurance plans and the VFC program may cover the vaccine for males, failure to do so could result in extremely low HPV vaccine coverage among adolescent males. This may be particularly true among families with lower incomes, as mothers reporting household incomes of less than $\$ 60,000$ were less willing to pay for HPV vaccine. Household income was not, however, associated with mothers' willingness to get their sons free HPV vaccine. HPV vaccination levels among adolescent females in the U.S. remain modest (about 37\% have received one or more doses [29]), despite most insurance health insurance plans covering the vaccine and high initial hypothetical acceptability to parents (55\% to 100\%) [30]. Future efforts should assess HPV vaccination levels among males to determine how acceptability of the vaccine to parents translates into vaccine uptake.

Regardless of whether HPV vaccine was free or cost money out of pocket, the strongest correlate of mothers' willingness was importance that the vaccine may protect their sons' future spouses or girlfriends from HPV-related disease. Currently, quadrivalent HPV vaccine is licensed for males only to prevent genital warts $[14,17,18]$, and parents have indicated that the vaccine's potential health benefits for their sons would be their main reason to vaccinate [26]. However, if future research supports HPV vaccine reducing cervical disease in males' sexual partners, it will be important to include this additional benefit in framing HPV vaccine to parents. This framing approach, however, may not be as effective among adult males, as informing them that HPV vaccine may benefit their female partners has not increased their willingness to get vaccinated in past studies [31,32]. Instead, informing adult males that HPV vaccine may prevent cancer in males, as opposed to only genital warts, could be an effective strategy (if future research supports this claim) [33]. 
Most mothers were not aware prior to the survey that boys could receive HPV vaccine, which was likely due to our survey being completed about two months following FDA approval of the vaccine for use in males. Mothers who were aware of this reported lower levels of willingness to get their sons free HPV vaccine, perhaps because mothers who were better informed had spent more time thinking about the potential costs and barriers as well as the benefits of vaccinating their sons. Interestingly, mothers who were aware did not have higher levels of knowledge about HPV and HPV vaccine compared to mothers who were not aware (data not shown). It is therefore possible that aware mothers were also less willing to vaccinate due to misinformation about HPV and HPV vaccine. Mothers with low knowledge who were willing to vaccinate may simply have high acceptability of vaccines for their children in general. Given that knowledge was generally low and greater knowledge was positively correlated with HPV vaccine acceptability, future educational efforts about HPV and HPV vaccine are needed for parents with adolescent sons. Such efforts may be especially beneficial for those mothers who are unsure about whether they would vaccinate their sons.

Mothers whose adolescent daughters had received HPV vaccine were more willing to get their sons HPV vaccine, likely due to these mothers having high overall opinions of HPV vaccine. Mothers who reported higher levels of importance of religion were less willing to get their sons free HPV vaccine. This finding coincides with HPV vaccine acceptability research among parents of females, where parents who attended religious services more frequently reported lower vaccine acceptability [34]. Non-Hispanic African American mothers were more willing to pay $\$ 400$ out of pocket for HPV vaccine, which is encouraging since it is more common for non-Hispanic African American males to have had an HPV type contained in the quadrivalent vaccine compared to other races [35]. While parents have generally been more willing to vaccinate older female adolescents against HPV [30], sons' age was not correlated with mothers' willingness.

\subsection{Strengths and Limitations}

Study strengths include the use of a sample from a national online survey panel, a high participation rate, that data collection occurred after FDA approval and provisional ACIP recommendations for males, and that we informed mothers about the vaccine's potential health benefits for males and their sexual partners prior to willingness items. Although the online panel closely resembles the U.S. population on many demographic features [36,37], most participants were non-Hispanic white and of fairly high socioeconomic status. The panel also regularly completes surveys, possibly including some health-related surveys, which might affect their responses. The item examining importance of HPV vaccine possibly protecting sons' future female partners from HPV-related disease may in part represent some aspect of overall HPV vaccine acceptability, though we believe this item measures an important parental belief. While we did not have information on some variables that may be related to HPV vaccine acceptability, such as sons' insurance coverage, the importance of a doctor's recommendation to get vaccinated, and beliefs about the vaccine (e.g., perceived effectiveness), some of these will become important only later as the vaccine is more widely understood by parents.

\subsection{Conclusions}

Mothers were moderately willing to get their sons HPV vaccine if it were free and much less willing if it cost money, suggesting that cost and health insurance coverage will be important factors in determining whether mothers get their sons vaccinated. Informing mothers that the vaccine may benefit their sons' sexual partners and increasing mothers' HPV and HPV vaccine knowledge could increase their willingness to get their sons vaccinated. Future 
research is needed to examine changes in acceptability of HPV vaccine for sons and vaccine uptake among males over time as more data become available on vaccine efficacy in males.

\section{Acknowledgments}

This study was primarily funded by a grant from the Centers for Disease Control and Prevention (CDC, 02577-10) with additional support for project staff from the American Cancer Society (MSRG-06-259-01-CPPB) and the Cancer Control Education Program at Lineberger Comprehensive Cancer Center (R25 CA57726). Members of the $\mathrm{CDC}$ were involved in conducting the study and in preparing and submitting this article. None of the other funding sources had a role in the design and conduct of the study; collection, management, analysis, and interpretation of the data; and preparation, review, or approval of the manuscript.

\section{References}

1. Cates W Jr. Estimates of the incidence and prevalence of sexually transmitted diseases in the United States. American Social Health Association Panel. Sex Transm Dis. 1999; 264 Suppl:S2-S7.

2. Dunne EF, Nielson CM, Stone KM, Markowitz LE, Giuliano AR. Prevalence of HPV infection among men: A systematic review of the literature. J Infect Dis. 2006; 194(8):1044-1057. [PubMed: 16991079]

3. Nielson CM, Harris RB, Dunne EF, Abrahamsen M, Papenfuss MR, Flores R, et al. Risk factors for anogenital human papillomavirus infection in men. J Infect Dis. 2007; 196(8):1137-1145. [PubMed: 17955431]

4. Partridge JM, Hughes JP, Feng Q, Winer RL, Weaver BA, Xi LF, et al. Genital human papillomavirus infection in men: incidence and risk factors in a cohort of university students. J Infect Dis. 2007; 196(8):1128-1136. [PubMed: 17955430]

5. Giuliano AR, Lu B, Nielson CM, Flores R, Papenfuss MR, Lee JH, et al. Age-specific prevalence, incidence, and duration of human papillomavirus infections in a cohort of 290 US men. J Infect Dis. 2008; 198(6):827-835. [PubMed: 18657037]

6. Parkin DM, Bray F. Chapter 2: The burden of HPV-related cancers. Vaccine. 2006; 24 Suppl 3:S3/11-S3/25. [PubMed: 16949997]

7. Watson M, Saraiya M, Ahmed F, Cardinez CJ, Reichman ME, Weir HK, et al. Using populationbased cancer registry data to assess the burden of human papillomavirus-associated cancers in the United States: overview of methods. Cancer. 2008; 113(10 Suppl):2841-2854. [PubMed: 18980203]

8. Brown DR, Schroeder JM, Bryan JT, Stoler MH, Fife KH. Detection of multiple human papillomavirus types in Condylomata acuminata lesions from otherwise healthy and immunosuppressed patients. J Clin Microbiol. 1999; 37(10):3316-3322. [PubMed: 10488198]

9. Lacey CJ, Lowndes CM, Shah KV. Chapter 4: Burden and management of non-cancerous HPVrelated conditions: HPV-6/11 disease. Vaccine. 2006; 24 Suppl 3:S3/35-S3/41. [PubMed: 16950016]

10. Dinh TH, Sternberg M, Dunne EF, Markowitz LE. Genital warts among 18- to 59-year-olds in the United States, national health and nutrition examination survey, 1999--2004. Sex Transm Dis. 2008; 35(4):357-360. [PubMed: 18360316]

11. Bosch FX, Castellsague X, Munoz N, de Sanjose S, Ghaffari AM, Gonzalez LC, et al. Male sexual behavior and human papillomavirus DNA: key risk factors for cervical cancer in Spain. J Natl Cancer Inst. 1996; 88(15):1060-1067. [PubMed: 8683637]

12. Habel LA, Van Den Eeden SK, Sherman KJ, McKnight B, Stergachis A, Daling JR. Risk factors for incident and recurrent condylomata acuminata among women. A population-based study. Sex Transm Dis. 1998; 25(6):285-292. [PubMed: 9662761]

13. Markowitz LE, Dunne EF, Saraiya M, Lawson HW, Chesson H, Unger ER, et al. Quadrivalent human papillomavirus vaccine: recommendations of the Advisory Committee on Immunization Practices (ACIP). MMWR Recomm Rep. 2007; 56(RR-2):1-24. [PubMed: 17380109]

14. Merck and Co. Inc. Gardasil prescribing information. 2009. Available at: http://www.merck.com/product/usa/pi_circulars/g/gardasil/gardasil_pi.pdf 
15. Giuliano, A.; Palefsky, J. on behalf of the male quadrivalent HPV vaccine efficacy trial study group. Abstract of presentation at the European Research Organization on Genital Infection and Neoplasia (EUROGIN) International Multidisciplinary Conference. Nice, France: 2008 November. The efficacy of quadrivalent HPV (types 6/11/16/18) vaccine in reducing the incidence of HPV infection and HPV-related genital disease in young men. http://www.eurogin.com

16. Palefsky, J.; Giuliano, A. on behalf of the male quadrivalent HPV vaccine efficacy trial study group. Abstract of presentation at the European Research Organization on Genital Infection and Neoplasia (EUROGIN) International Multidisciplinary Conference. Nice, France: 2008 November. Efficacy of the quadrivalent HPV vaccine against HPV 6/11/16/18-related genital infection in young men. http://www.eurogin.com

17. Centers for Disease Control and Prevention. ACIP provisional recommendations for HPV vaccine. 2009. Available at: http://www.cdc.gov/vaccines/recs/provisional/downloads/hpv-vac-dec2009-508.pdf

18. Centers for Disease Control and Prevention. FDA licensure of quadrivalent human papillomavirus vaccine (HPV4, Gardasil) for use in males and guidance from the Advisory Committee on Immunization Practices (ACIP); MMWR Morb Mortal Wkly Rep. 2010. p. 630-632.

19. Liddon N, Hood J, Wynn BA, Markowitz LE. Acceptability of human papillomavirus vaccine for males: a review of the literature. J Adolesc Health. 2010; 46(2):113-123. [PubMed: 20113917]

20. Podolsky R, Cremer M, Atrio J, Hochman T, Arslan AA. HPV vaccine acceptability by Latino parents: a comparison of U.S. and Salvadoran populations. J Pediatr Adolesc Gynecol. 2009; 22(4):205-215. [PubMed: 19646665]

21. The American Association for Public Opinion Research. Standard definitions: final dispositions of case codes and outcome rates for surveys. 6th edition. AAPOR; 2009.

22. Keating KM, Brewer NT, Gottlieb SL, Liddon N, Ludema C, Smith JS. Potential barriers to HPV vaccine provision among medical practices in an area with high rates of cervical cancer. $\mathrm{J}$ Adolesc Health. 2008; 43(4 Suppl):S61-S67. [PubMed: 18809147]

23. Fazekas KI, Brewer NT, Smith JS. HPV vaccine acceptability in a rural Southern area. J Womens Health (Larchmt). 2008; 17(4):539-548. [PubMed: 18370586]

24. Reiter PL, Brewer NT, Gottlieb SL, McRee AL, Smith JS. Parents' health beliefs and HPV vaccination of their adolescent daughters. Soc Sci Med. 2009; 69(3):475-480. [PubMed: 19540642]

25. Office of Management and Budget. Standards for defining metropolitan and micropolitan statistical areas; notice; Federal Register. 2000 December 27. p. 82227-82238.Available at: http://www.whitehouse.gov/omb/fedreg/metroareas122700.pdf

26. Watts LA, Joseph N, Wallace M, Rauh-Hain JA, Muzikansky A, Growdon WB, et al. HPV vaccine: A comparison of attitudes and behavioral perspectives between Latino and non-Latino women. Gynecol Oncol. 2009; 112(3):577-582. [PubMed: 19150120]

27. Slomovitz BM, Sun CC, Frumovitz M, Soliman PT, Schmeler KM, Pearson HC, et al. Are women ready for the HPV vaccine? Gynecol Oncol. 2006; 103(1):151-154. [PubMed: 16551476]

28. Gerend MA, Weibley E, Bland H. Parental response to human papillomavirus vaccine availability: uptake and intentions. J Adolesc Health. 2009; 45(5):528-531. [PubMed: 19837361]

29. Centers for Disease Control and Prevention (CDC). National, state, and local area vaccination coverage among adolescents aged 13-17 years--United States, 2008. MMWR Morb Mortal Wkly Rep. 2009; 58(36):997-1001. [PubMed: 19763075]

30. Brewer NT, Fazekas KI. Predictors of HPV vaccine acceptability: a theory-informed, systematic review. Prev Med. 2007; 45(2-3):107-114. [PubMed: 17628649]

31. Gerend MA, Barley J. Human papillomavirus vaccine acceptability among young adult men. Sex Transm Dis. 2009; 36(1):58-62. [PubMed: 18830138]

32. Jones M, Cook R. Intent to receive an HPV vaccine among university men and women and implications for vaccine administration. J Am Coll Health. 2008; 57(1):23-32. [PubMed: 18682342]

33. McRee AL, Reiter PL, Chantala K, Brewer NT. The influence of disease outcome framing on HPV vaccine acceptability among men. Cancer Epidemiol Biomarkers Prev. In press. 
34. Constantine NA, Jerman P. Acceptance of human papillomavirus vaccination among Californian parents of daughters: a representative statewide analysis. J Adolesc Health. 2007; 40(2):108-115. [PubMed: 17259050]

35. Markowitz LE, Sternberg M, Dunne EF, McQuillan G, Unger ER. Seroprevalence of human papillomavirus types 6,11,16, and 18 in the United States: National Health and Nutrition Examination Survey 2003-2004. J Infect Dis. 2009; 200(7):1059-1067. [PubMed: 19719390]

36. Baker, LC.; Bundorf, MK.; Singer, S.; Wagner, TH. Validity of the survey of health and internet and Knowledge Network's panel and sampling. 2003. Available at: http://www.knowledgenetworks.com/ganp/docs/Appendix \%20Survey\%20of\%20Health\%20and $\% 20$ the\%20Internet.pdf

37. Dennis, JM. Description of within-panel survey sampling methodology: the Knowledge Networks approach. 2009. Available at:

http://www.knowledgenetworks.com/ganp/docs/KN-Within-Panel-Survey-SamplingMethodology.pdf 


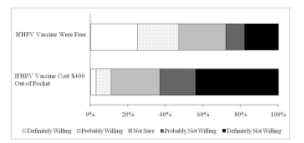

Figure 1.

Mothers' willingness to get their adolescent sons human papillomavirus (HPV) vaccine $(n=406)$. 
Table 1

Characteristics of mothers and their adolescent sons $(n=406)$.

\begin{tabular}{|c|c|}
\hline & $\mathrm{n}(\%)$ \\
\hline \multicolumn{2}{|l|}{ Son Characteristics } \\
\hline \multicolumn{2}{|l|}{ Age (Years) } \\
\hline $9-12$ & $171(42)$ \\
\hline $13-15$ & $126(31)$ \\
\hline $16-18$ & $109(27)$ \\
\hline \multicolumn{2}{|l|}{$\begin{array}{l}\text { Sister Aged 11-14 Years Received Any Doses of HPV } \\
\text { Vaccine }\end{array}$} \\
\hline No/Don't Know $(n=8)$ & $284(70)$ \\
\hline Yes & $122(30)$ \\
\hline \multicolumn{2}{|l|}{ Mother Characteristics } \\
\hline \multicolumn{2}{|l|}{ Age (Years) } \\
\hline$<40$ & $119(29)$ \\
\hline $40-49$ & $238(59)$ \\
\hline $50+$ & $49(12)$ \\
\hline \multicolumn{2}{|l|}{ Race/Ethnicity } \\
\hline White, Non-Hispanic & $321(79)$ \\
\hline African American, Non-Hispanic & $27(7)$ \\
\hline Other Race, Non-Hispanic & $23(6)$ \\
\hline Hispanic & $35(9)$ \\
\hline \multicolumn{2}{|l|}{ Marital Status } \\
\hline Divorced, Widowed, Separated, Never Married & $45(11)$ \\
\hline Married or Living with Partner & $361(89)$ \\
\hline \multicolumn{2}{|l|}{ Education Level } \\
\hline No College Degree & $202(50)$ \\
\hline College Degree & $204(50)$ \\
\hline \multicolumn{2}{|l|}{ Employment Status } \\
\hline Not Currently Employed & $136(33)$ \\
\hline Currently Employed & $270(67)$ \\
\hline \multicolumn{2}{|l|}{ Born-again Christian } \\
\hline No/Don't Know $(n=1)$ & $261(64)$ \\
\hline Yes & $145(36)$ \\
\hline Importance of Religion ${ }^{a}$, mean (SD) & $3.3(1.0)$ \\
\hline Political Affiliation ${ }^{b}$, mean (SD) & $2.4(1.1)$ \\
\hline \multicolumn{2}{|l|}{ Ever Had an Abnormal Pap Smear } \\
\hline No/Don't Know $(n=3)$ & $264(65)$ \\
\hline Yes & $142(35)$ \\
\hline HPV and HPV Vaccine Knowledge ${ }^{c}$, mean (SD) & $1.3(0.9)$ \\
\hline \multicolumn{2}{|l|}{ Aware HPV Vaccine Can Be Given to Boys } \\
\hline No/Don't Know $(n=1)$ & $344(85)$ \\
\hline
\end{tabular}




\begin{tabular}{lr}
\hline & $\mathbf{n}(\%)$ \\
\hline Yes & $62(15)$ \\
Talked with Son About HPV Vaccine & \\
No/Don't Know $(n=3)$ & $366(90)$ \\
Yes & $40(10)$ \\
Importance that HPV Vaccine Could Protect Son's Future & $3.0(1.1)$ \\
Spouse or Girlfriend ${ }^{a}$, mean (SD) & \\
Household Characteristics & \\
Household Income & \\
$<\$ 60,000$ & $138(34)$ \\
$\geq \$ 60,000$ & $268(66)$ \\
Urbanicity & \\
Rural & $57(14)$ \\
Urban & $349(86)$ \\
Region of Residence & \\
Northeast & $63(16)$ \\
Midwest & $127(31)$ \\
West & $116(29)$ \\
South & $100(25)$ \\
\hline
\end{tabular}

Note. $\mathrm{HPV}=$ human papillomavirus, $\mathrm{SD}=$ standard deviation.

${ }^{a}$ Response scale: not important at all (coded as 1), slightly important (2), fairly important (3), very important (4).

${ }^{b}$ Response scale: very conservative (coded as 1), somewhat conservative (2), moderate (3), somewhat liberal (4), very liberal (5).

${ }^{c}$ Knowledge score calculated by summing the number of correct responses to three items. 


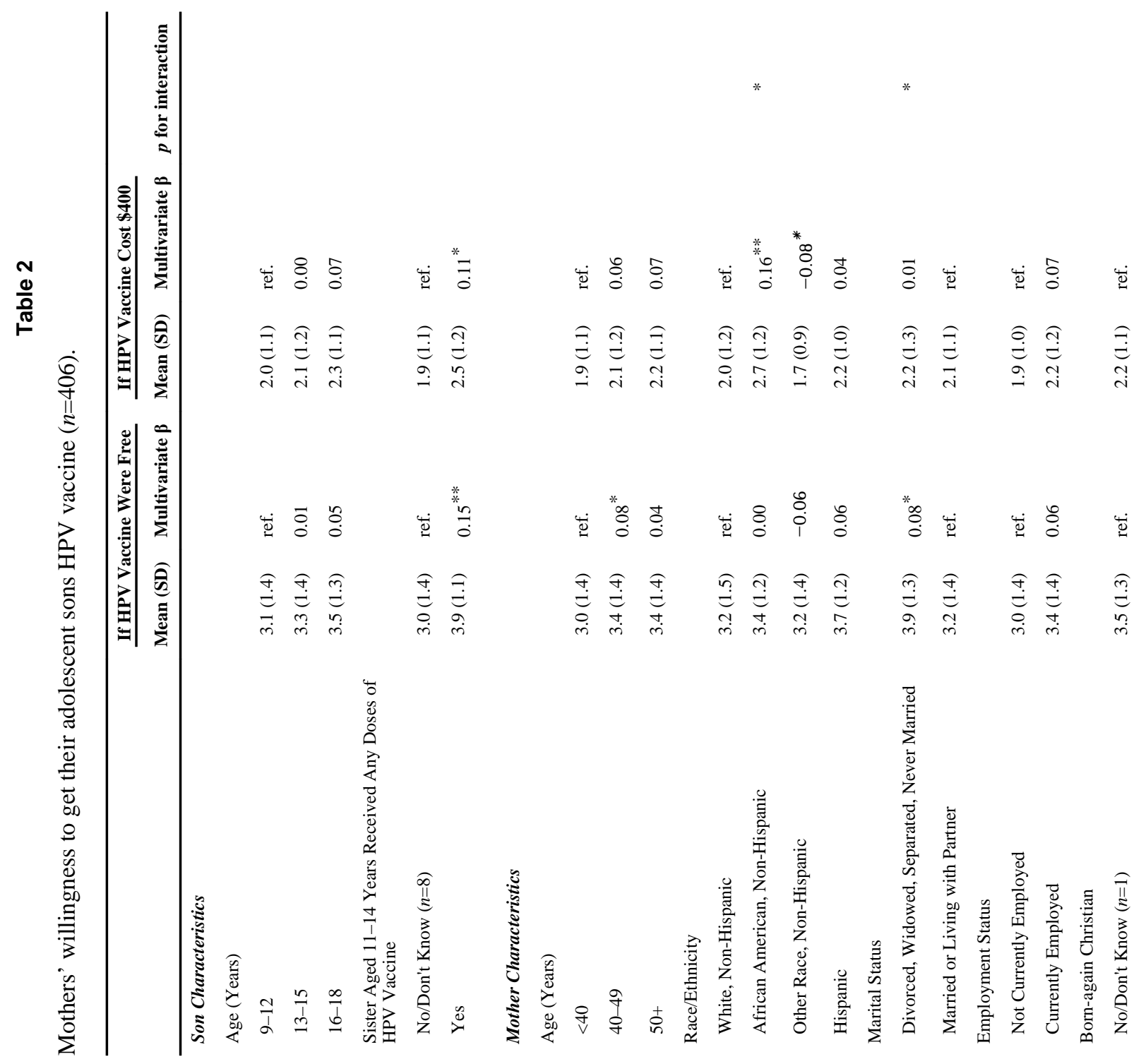




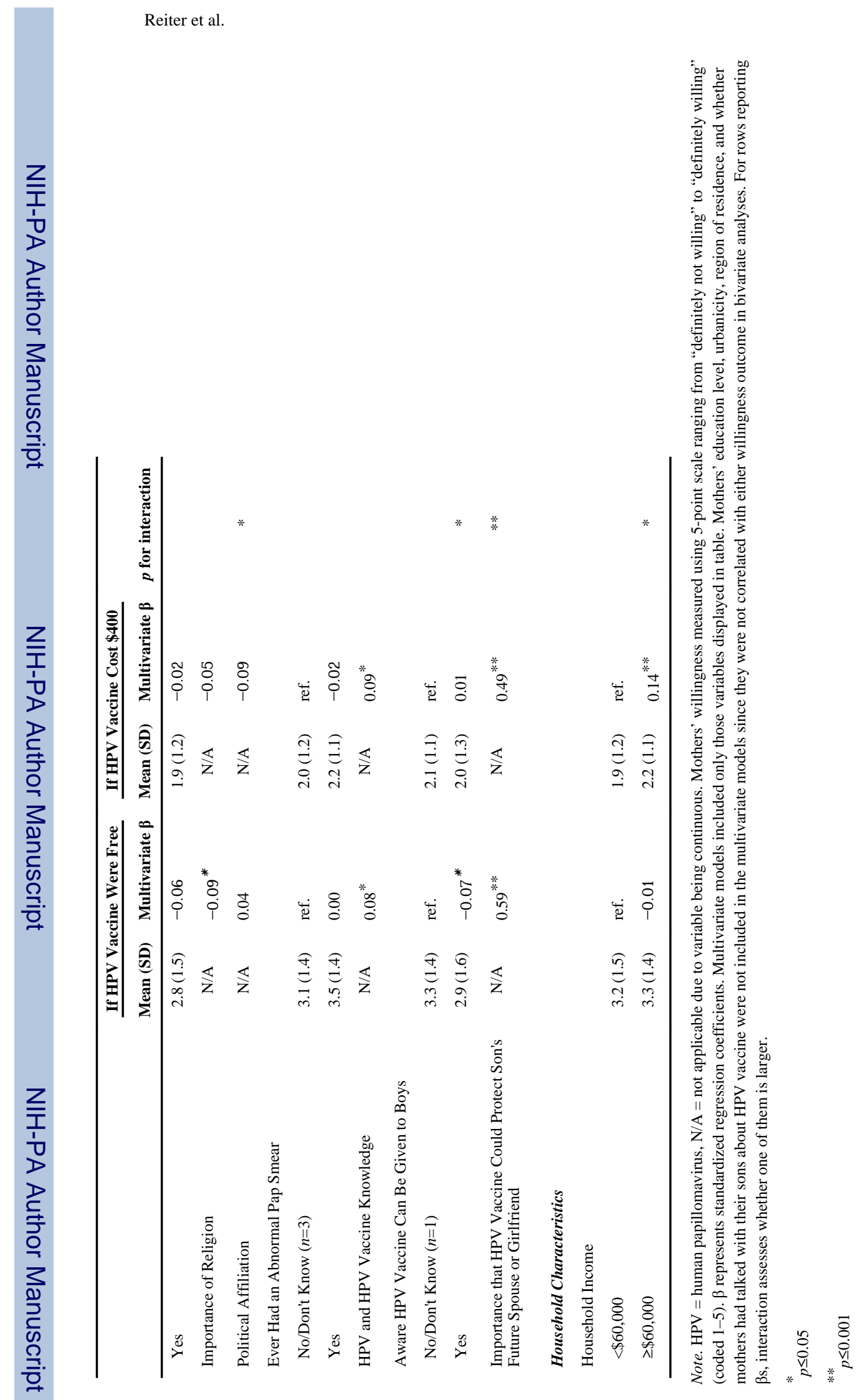

Vaccine. Author manuscript; available in PMC 2011 August 31. 